Received: 04.12.2019

Revised: 18.02 .2020

Accepted: 06.03.2020

DOI: $10.17804 / 2410-9908.2020 .2 .019-025$

\title{
INCREASING LOAD-CARRYING ABILITY OF GEAR COUPLINGS
}

\author{
G. N. Makarov ${ }^{1}$, V. V. Grib ${ }^{2, \text { a) }}$ and M. G. Shalygin ${ }^{3, \text { b)* }}$ \\ ${ }^{1}$ Nokia Solutions and Networks JSC, Bryansk, Russian Federation \\ ${ }^{2}$ Moscow Automobile and Road Construction State Technical University (MADI), \\ 64 Leningradskiy Ave., 125319, Moscow, Russian Federation \\ ${ }^{3}$ Bryansk State Technical University, 7, 50-letiya Oktyabrya Blvd, 241035, Bryansk, Russian Federation \\ a) (iD http://orcid.org/0000-0002-4252-2849; \\ b) (iD http://orcid.org/0000-0002-8102-9918
}

\begin{abstract}
*Corresponding author. E-mail: migshalygin@yandex.ru
Address for correspondence: Bryansk State Technical University, 7 50-letiya Oktyabrya Blvd, 241035, Bryansk, Russia Tel.: +7903868 8568
\end{abstract}

A method for increasing the load-carrying capacity of gear couplings by reducing maximum contact stresses is considered. The method is based on the use in the design of a gear box coupling, the teeth of which have three annular grooves made along a closed helix. This design allows you to give the teeth an elastic damping properties necessary to compensate for the uneven distribution of the load across the width of the tooth, due to the peculiarities of the operation of gear couplings. A solution to the problem of the elastic contact of two teeth of a gear coupling is given using the SolidWorks simulation finite element analysis software system. It has been established that the separation of the teeth of the gear cage by annular grooves makes it possible to reduce the magnitude of the contact stresses by $13.1-15.4 \%$, and this indicates the feasibility of using the design proposed by the authors in gear couplings.

Keywords: load-carrying ability, contact pressure, gear coupling.

\section{References}

1. Popov A.P., Savenkov O.I. Experimental research of the load-carrying ability of gear couplings. Vestnik Inzhenernoy Akademii Ukrainy, 2010, nos. 3-4, pp. 203-209. (In Russian).

2. Popov A.P., Savenkov O.I. Contact strength of gear couplings with longitudinal teeth modification. MOTROL, 2013, vol. 13A, pp. 167-176. (In Russian).

3. Popov A.P., Mironenko A.I., Savenkov O.I. Contact stiffness of gear transmissions in view of the effect of tooth misalignment. Vestnik Natsionalnogo Tekhnicheskogo Universiteta "Kharkovskiy Politekhnicheskiy Institut”. Seriya: Problemy Mekhanicheskogo Privoda. - 2016. - No. 23 (1195). - P. 121-125. (In Russian).

4. Borodin A.V. Taruta D.V., Velgodskaya T.V. Increase bearing ability of tooth gearing of a traction reducer of the locomotive. Izvestiya Transsiba, 2010, № 3 (3). - P. 7-12. (In Russian).

5. Gorlenko O.A. Makarov G.N. Increase of wear resistance of spur gears. Izvestiya Moskovskogo Gosudarstvennogo Tekhniheskogo Universiteta, 2014, vol. 2, no. 2 (20), pp. 21-25. (In Russian).

6. Gorlenko O.A., Makarov G.N., and Shnyrikov I.O. Improving the contact endurance of the teeth of spur cylindrical gears. Trenie Smazka Mash. Mekh., 2014, no. 6, pp. 25-27. (In Russian).

7. Malinkovich M.D. Study of the process of cylindrical gears engagement. Bull BSTU, 2008, iss. 3 (19), pp. 32-37. (In Russian).

8. Gorlenko O.A., Shalygin M.G., Makarov G.N. Removing contact of edge of teeth of planetary transmissions. Stroitelnye i Dorozhnye Mashiny, 2017, no. 8, pp. 38-42. (In Russian). 
9. Gorlenko O.A., Shalygin M.G., Makarov G.N. Eliminating Liquid Entrapment between the Teeth of a Gear-Driven Pump. Russian Engineering Research, 2018, vol. 38, no. 7, pp. 499-502. DOI: $10.3103 / \mathrm{S} 1068798 X 18070079$. 
Подана в журнал: 04.12.2019

УДК 621.825 .56

DOI: $10.17804 / 2410-9908.2020 .2 .019-025$

\title{
ПОВЫШЕНИЕ НАГРУЗОЧНОЙ СПОСОБНОСТИ ЗУБЧАТЫХ МУФТ
}

\author{
Г. Н. Макаров ${ }^{1}$, В. В. Гриб ${ }^{2, \text { a) }}$, М. Г. Шалыгин ${ }^{3, \text { б)* }}$ \\ ${ }^{I}$ AO «Нокиа Солюшнз энд Нетворкс», г. Брянск, Российская Федерация \\ ${ }^{2}$ Московский автомобильно-дорожный государственный технический университет (МАДИ), \\ 2. Москва, Российская Федерация \\ ${ }^{3}$ Брянский государственный технический университет, г. Брянск, Российская Федерация \\ a) (iD http://orcid.org/0000-0002-4252-2849; \\ б) (iD http://orcid.org/0000-0002-8102-9918
}

\begin{abstract}
*Ответственный автор. Электронная почта: migshalygin@yandex.ru
Адрес для переписки: Брянский государственный технический университет, 241035, Россия, г. Брянск, бульвар 50 лет Октября, 7; Тел.: +7-903-868-85-68
\end{abstract}

Рассмотрен способ повышения нагрузочной способности зубчатых муфт, путем уменьшения величины максимальных контактных напряжений. Способ основан на применении в конструкции муфты зубчатой обоймы, зубья которой имеют три кольцевые канавки, выполненные по замкнутой винтовой линии. Такая конструкция позволяет наделить зубья упругодемпфирующими свойствами, необходимыми для компенсации неравномерного распределения нагрузки по ширине зуба, обусловленного особенностями работы зубчатых муфт. Дано решение задачи упругого контакта двух зубьев зубчатой муфты помощью программной системы конечно-элементного анализа SOLIDWORKS simulation. Установлено, что разделение зубьев зубчатой обоймы кольцевыми канавками позволяет уменьшить величину контактных напряжений на 13,1-15,4 \%, что свидетельствует о целесообразности применения предложенной авторами конструкции в зубчатых муфтах.

Ключевые слова: нагрузочная способность, контактное давление, зубчатая муфта.

\section{1. Введение}

На современном этапе развития промышленности зубчатые муфты получают все большее распространение. Они применяются в различных механизмах и машинах и представляют собой зубчатые механизмы с передаточным отношением равным единице, являющиеся ответственными узлами, часто определяющими надежность и долговечность всей машины. Сдерживающими факторами более широкого применения зубчатых муфт является ограничение по нагрузочной способности при повышенных углах перекоса соединяемых валов.

При работе зубчатых муфт, вследствие перекоса осей соединяемых валов, происходят относительные угловые и тангенциальные смещения зубьев зубчатой втулки относительно зубчатой обоймы, величина которых возрастает по мере износа сопряжений соединяемых агрегатов [3]. Это приводит к уменьшению величины фактической площадки контакта и ее смещению к кромке зубьев, что является причиной возрастания максимальных контактных напряжений в зацепление $[1,2]$.

В работах [4-8] предлагается конструкция зубчатого колеса, позволяющая повысить нагрузочную способность зубчатой передачи за счет наделения зубьев дополнительной изгибной податливостью, тем самым венец зубчатого колеса получает дополнительную степень свободы, что ведет к ослаблению кромочного взаимодействия зубьев. Для того чтобы изготовить данное зубчатое колесо необходимо разрезать зубья кольцевыми канавками, выполненными по замкнутой винтовой линии, расположенными в плоскостях, параллельных плос- 
костям движения колеса $[8,9]$. Применение в зубчатых муфтах обойм с зубьями, разделенными на части, позволит повысить число зубьев, одновременно находящихся в работе, и приведет к выравниванию нагрузки по ширине контактирующих зубьев (рис. 1). При этом каждая часть зуба будет работать как отдельное зацепление и приспосабливаться к изменяющимся условиям работы $[6,7]$.

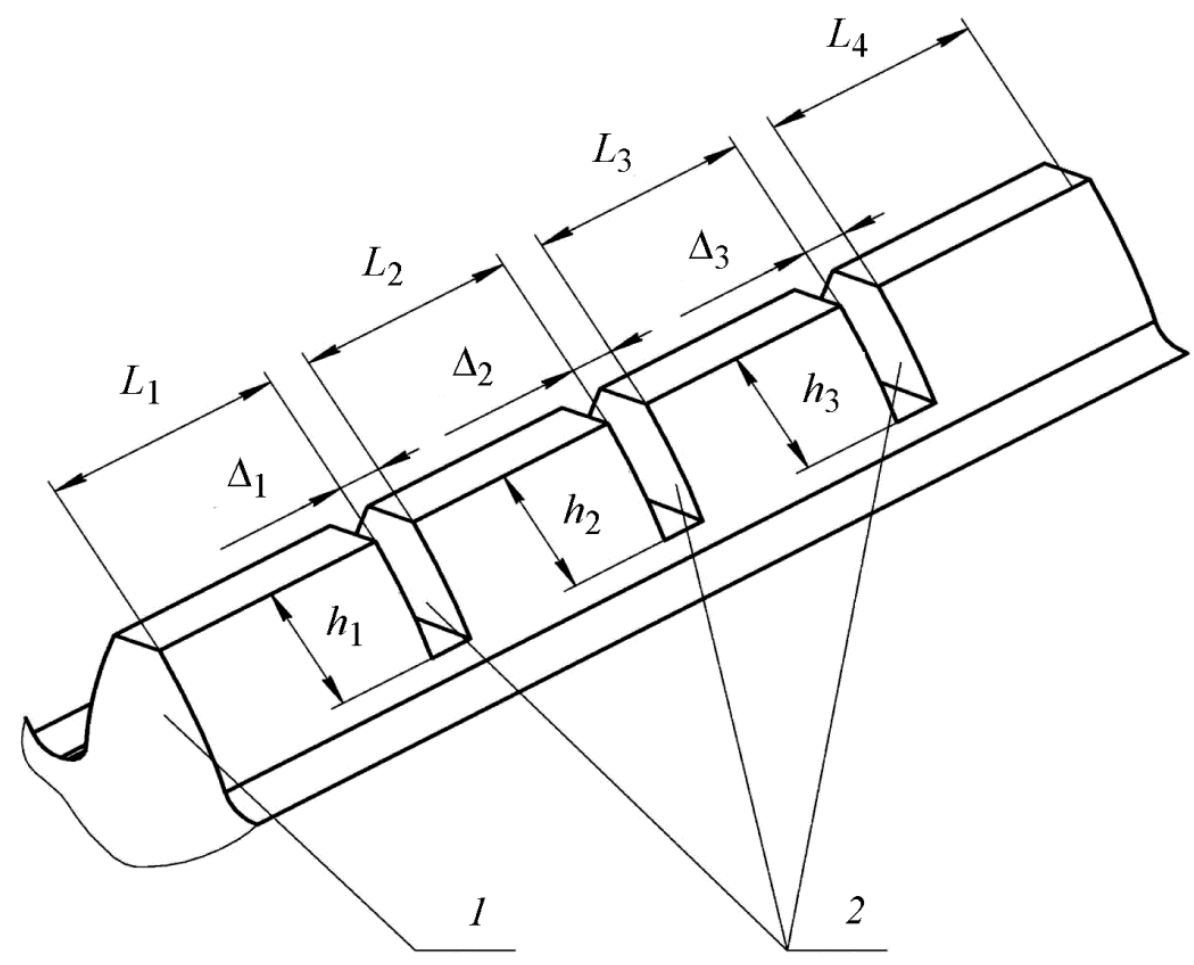

Рис. 1. Зуб зубчатой обоймы с кольцевыми канавками: 1 - венец зубчатого колеса; 2 - кольцевые канавки; $L_{1}=L_{2}=L_{3}=L_{4}$ - размеры участков; $h_{1}=h_{2}=h_{3} h_{4}=1,5 \mathrm{~m}$ глубина кольцевых канавок (здесь $m$ - модуль зубчатого колеса); $\Delta_{1}=\Delta_{2}=\Delta_{3}=1 \mathrm{мм}-$ ширина кольцевых канавок

Однако в литературных источниках отсутствуют данные о влиянии кольцевых канавок в зубьях зубчатой обоймы на нагрузочную способность зубчатых муфт. Поэтому оценка влияния кольцевых канавок в зубчатой обойме на нагрузочную способность муфты является актуальной задачей.

Разработка и создание высоконагруженных зубчатых муфт, предназначенных для эксплуатации в условиях перекоса осей соединяемых валов агрегатов, является актуальной проблемой. Эта проблема является неразрывной составной частью существующих в настоящее время научных программ и заданий практически во всех отраслях машиностроения, выпускающих зубчатые муфты. Для успешного решения указанной проблемы необходимо проводить анализ новых технических решений, направленных на повышение нагрузочной способности зубчатых муфт.

Поэтому авторами была решена задача определения величины максимальных контактных давлений для сопряжений «зуб зубчатой втулки - зуб зубчатой обоймы» и «зуб зубчатой втулки - зуб зубчатой обоймы с кольцевыми канавками».

\section{2. Материалы и методика}

В качестве объекта исследования рассматривается судовая зубчатая муфта, для которой в работе [2] определены параметры муфты (табл. 1). 
Таблица 1 - Параметры зацепления зубьев судовой зубчатой муфты

\begin{tabular}{|l|c|}
\hline \multicolumn{1}{|c|}{ Параметр } & Величина \\
\hline Модуль, мм & 6 \\
\hline Число зубьев & 20 \\
\hline Угол профиля исходного контура, град. & 45 \\
\hline Ширина зубьев зубчатой втулки, мм & 50 \\
\hline Ширина зубьев зубчатой обоймы, мм & 3000 \\
\hline Радиус бочкооборазности, мм & Сталь 18ХНВА ГОСТ 4543-71 \\
\hline Материал & $2,1 \times 10^{5}$ \\
\hline Модуль упругости, МПа & 0,28 \\
\hline Коэффициент Пуассона & \\
\hline
\end{tabular}

Предметом исследования является величина максимальных контактных напряжений в контакте двух зубьев. В качестве метода исследований применялся метод конечноэлементного (КЭ) моделирования с помощью программной системы конечно-элементного анализа SOLIDWORKS simulation.

Геометрическая модель зуба представляет собой зуб эвольвентного профиля на массивном основании. В модели зацепления рабочие поверхности зубьев вводятся в контакт, а поверхности основания используются для задания граничных условий. Для построения геометрической модели зуба использовался инструмент КОМПАС shaft-3D. Структура КЭ сетки для зуба зубчатой обоймы с кольцевыми канавками представлена на рис. 2. Сгущение сетки создавалось в области, «накрывающей» пятно контакта, чтобы обеспечить более точное вычисление контактных давлений.

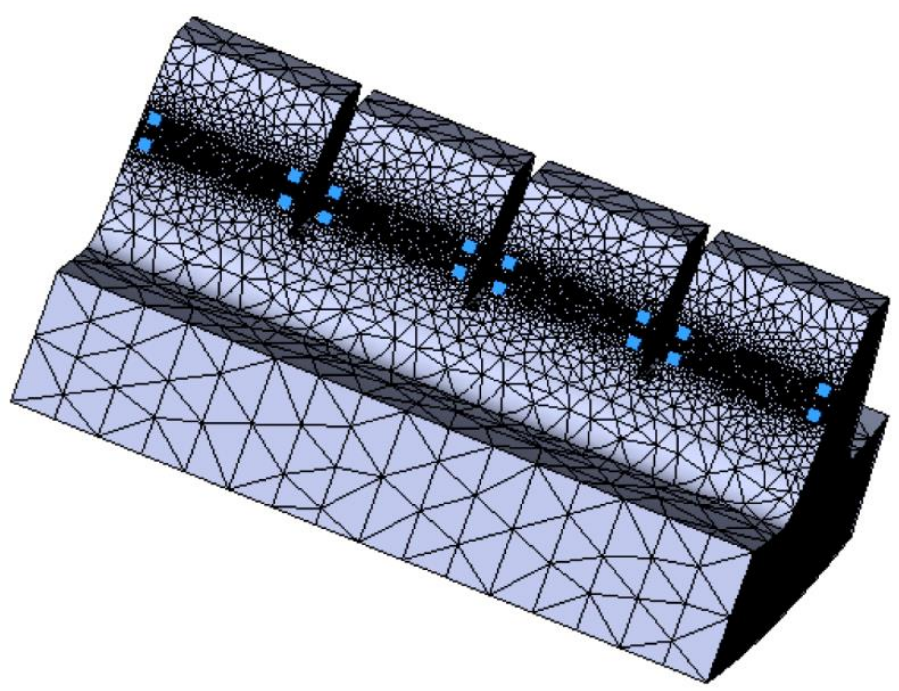

Рис. 2. Конечно-элементная модель зуба обоймы с кольцевыми канавками

Граничные условия задавались в узлах сетки, лежащих на контурах поверхности оснований. Узлы зубчатой обоймы закреплялись по трем линейным степеням свободы. Для линейных перемещений узлов зубчатой втулки уравнения связи задавались так, чтобы у них оставалась вращательная степень свободы относительно оси втулки. Нагрузка прикладывалась к узлам зубчатой втулки равномерно, чтобы обеспечить момент, приложенный ко втулке. 


\section{3. Результаты и обсуждения}

При изготовлении зубчатых муфт их зубьям присущи накопленные погрешности окружных шагов, которые приводят к неравномерному распределению усилий между зубьями, величины указанных погрешностей определяются точностью изготовления зубьев. Указанная неравномерность носит постоянный характер и не изменяется при вращении зубчатой муфты. В связи с этим усилие, действующее на максимально нагруженную пару зубьев вследствие ошибок при их изготовлении, складывается поочередно с усилиями, действующими на каждую сопряженную пару зубьев при перекосах осей. Неточность изготовления зубьев, оказывает отрицательное влияние на нагрузочную способность зубчатых муфт, значительно уменьшая ее. Поэтому при расчетах необходимо учитывать, что зубья зубчатой втулки и зубчатой обоймы входят в контакт под некоторым углом перекоса.

Для оценки влияния кольцевых канавок в зубьях обоймы зубчатой муфты на величину контактных напряжений в зацеплении рассматривались следующие варианты сопряжений зубьев:

- зуб зубчатой втулки - зуб зубчатой обоймы без модификации;

- зуб зубчатой втулки - зуб зубчатой обоймы с кольцевыми канавками.

Для каждого варианта сопряжений суммарный угол перекоса осей принимался равным $\psi=8,7 \cdot 10^{-3}$ рад. [2], нагружение осуществлялось вращающими моментами 100, 200 и $300 \mathrm{H} \cdot$ м. Результаты расчетов представлены на рис. 3.

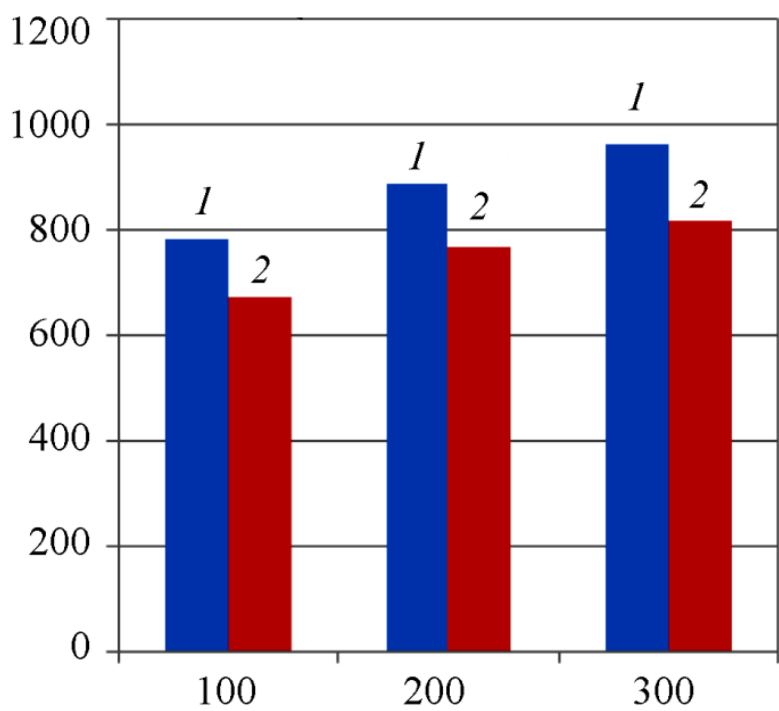

Крутящий момент

Рис. 3. Величина контактных напряжений, МПа: 1 - зуб зубчатой втулки - зуб зубчатой обоймы без модификации; 2 - зуб зубчатой втулки - зуб зубчатой обоймы с кольцевыми канавками

Таблица 2 - Результаты расчета

\begin{tabular}{|c|c|c|}
\hline \multirow{2}{*}{$\begin{array}{c}\text { Крутящий } \\
\text { момент }\end{array}$} & \multicolumn{2}{|c|}{ Величина контактных напряжений, МПа } \\
\cline { 2 - 3 } & Зуб зубчатой втулки - зуб зубчатой обоймы \\
\hline 100 & без модификации & с кольцевыми канавками \\
\hline 200 & 785,2 & 674,3 \\
\hline 300 & 886,4 & 766,9 \\
\hline
\end{tabular}


Таким образом, разделение зубьев зубчатой втулки кольцевыми канавками позволяет снизить величину контактных напряжений на 13,1-15,4 \% при наличии угла перекоса обоймы относительно втулки, что свидетельствует о возможности повышения нагрузочной способности зубчатых муфт, что может быть особенно актуально в реальных условиях эксплуатации при значительных внешних динамических воздействиях.

\section{4. Заключение}

В статье рассмотрена конструкция зубчатой муфты, не имеющая аналогов в современном машиностроении. Отличительной особенностью конструкции является наличие кольцевых канавок, выполненных по замкнутой винтовой линии, в зубья зубчатой обоймы муфты, что позволило уменьшить величину контактных напряжений на 13,1-15,4 \% при наличии угла перекоса обоймы относительно втулки, в среднем на 120 МПа. Доказана целесообразность применения данной конструкции с целью повышения нагрузочной способности муфты.

\section{Литература}

1. Попов А. П., Савенков О. И. Экспериментальное исследование нагрузочной способности зубчатых муфт // Вестник Инженерной академии Украины. - 2010. - № 3-4. - С. 203-209.

2. Попов А., Савенков О. Контактная прочность зубчатых муфт с продольно модифицированными зубьями // MOTROL. - 2013. - Vol. 13A. - C. 167-176.

3. Попов А. П., Мироненко А. И., Савенков О. И. Контактная жесткость зубчатых передач с учетом влияния перекосов зубьев // Вестник национального технического университета «Харьковский политехнический институт». Серия: Проблемы механического привода. 2016. - № 23 (1195). - С. 121-125.

4. Бородин А. В., Тарута Д. В., Вельгодская Т. В. Повышение несущей способности зубчатой передачи тягового редуктора тепловоза // Известия Транссиба. - 2010. - № 3 (3). C. 7-12.

5. Горленко О. А., Макаров Г. Н. Повышение износостойкости прямозубых цилиндрических зубчатых передач // Известия Московского государственного технического университета. 2014. - T. 2, № 2 (20). - С. 21-25.

6. Макаров Г. Н., Шныриков И. О., Горленко О. А. Повышение контактной выносливости зубьев прямозубых цилиндрических зубчатых передач // Трение и смазка в машинах и механизмах. - 2014. - № 6. - С. 25-27.

7. Малинкович М. Д. Исследование процесса зацепления цилиндрических зубчатых передач // Вестник Брянского государственного технического университета. - 2008. - Вып. 3. C. $32-37$.

8. Горленко О. А., Шалыгин М. Г., Макаров Г. Н. Устранение кромочного контакта зубчатых колес планетарных передач // Строительные и дорожные машины. - 2017. - № 8. C. $38-42$.

9. Gorlenko O. A., Shalygin M. G., Makarov G. N. Eliminating Liquid Entrapment between the Teeth of a Gear-Driven Pump // Russian Engineering Research. - 2018. - Vol. 38, no. 7. P. 499-502. - DOI: 10.3103/S1068798X18070079. 